\title{
The Practical Research of Situational Simulation Teaching Method in the Course of Customer Relation Management
}

\author{
Mei Zhao \\ College of Economics and Management \\ Yunnan Agricultural University \\ Kunming 650201
}

\author{
Xinggui Liu * \\ College of Science \\ Yunnan Agricultural University \\ Kunming 650201
}

\begin{abstract}
The purpose of this article is to explore the implementation steps, effects and problems of scenario simulation teaching method in the course of Customer Relationship Management, so as to provide a new mode and method for the teaching of e-commerce and other specialties. Through the research, the following conclusions are drawn: the application of situational simulation teaching method in the course of Customer Relationship Management is conducive to the cultivation of applied innovative talents and stimulate students' initiative in learning. Students have become the leading role in classroom teaching, thus realizing the transformation from knowledge to ability. The innovation of this paper lies in discussing the evaluation index system of scenario simulation effect.
\end{abstract}

Keywords-scenario simulation teaching method; customer relationship management; application; effect

\section{INTRODUCTION}

With the continuous development of economic globalization, competition among enterprises have become fierce increasingly, and the market has changed from productcentered to customer-centered. In the modern society with developed market economy, customers' demands are diversified increasingly and products are more and more scientific, which makes customer relationship management more and more important in enterprises. Through customer relationship management, continuous communication with customers, continuous understanding of customer needs, and continuous improvement and improvement of products and services, we can meet the continuous needs of customers. Through the study of Customer Relationship Management, students can learn the theoretical knowledge of customer relationship management systematically, establish the business concept of "customer first", master the application skills of how to identify customers, establish and maintain relationships with customers, provide a basis for future work, better customer service and customer management.

With the change of the demand for talents in the process of social development, the training of applied talents has become one of the main directions of education mode reform at the present stage. E-commerce specialty needs to strengthen the practical teaching content while building the basic theoretical knowledge system, realize the training concept of paying

This is the result of the Phase Study of the Educational and Teaching Reform Project of Yunnan Agricultural University (2017YAUJY107) equal attention to both theoretical and applied talents, and meet the needs of new e-commerce talents under the market economic system.

How to make students possess the knowledge, ability and accomplishment of customer relationship management, teaching method is very important[1] . Traditional inculcation teaching method has been difficult to meet the needs of training. The situational simulation teaching method is an effective teaching method which is suitable for the teaching objectives and characteristics of the course of Customer Relationship Management. It can break through the traditional teaching thinking of teachers and improves the effectiveness of teaching. Based on the practical experience of situational simulation teaching in the course of Customer Relationship Management, the author discusses the key links and main problems in the teaching process.

\section{The Concept OF Situational Simulation TEACHING METHOD}

Scenario simulation teaching method was first applied in the field of psychology research, which was first proposed by American psychologist Horn[2]. The main body of scenario simulation teaching method is students. The core of scenario simulation teaching method is to let students play various roles. By setting certain work scenarios, students play different roles can experience the situation of work and their sense of role. It can accumulate experience for their future work in customer relationship management.

Using scenario simulation teaching method, we can understand the rigid theory in the form of scenario reproduction, and find the solution to the problem in the simulation practice[3]. Students integrate into the actual role of customer relationship management gradually. They can understand and experience preliminary how to communicate with customers effectively and handle customers' complaint. Situational teaching method students become the masters of the classroom, teachers through inspiration, guidance, prompting, summary, etc., students independently summarize, to achieve the purpose of understanding the knowledge learned. At the same time, through situational simulation teaching, students can participate in the classroom, activate the classroom atmosphere, truly understand why customers 
complain, how to deal with customer complaints actively, how to carry out preventive management and other practical problems. By guiding the students to participate actively, the students who participated in the simulation were given extra marks in their usual grades, so as to stimulate the students' initiative in learning and achieve the goal of improving the teaching effect. In the simulation, students' organizational ability, language expression ability, teamwork ability and stage performance ability are improved, and their abilities are exercised and improved, which adds weight to the success rate of employment and entrepreneurship.

Teachers can't satisfy students 'requirements by teaching knowledge in class, and they can't let students feel how to improve customer value, satisfy customers and deal with customers' complaints in practice. In order to make students learn in a close to the real problem scenario, it is necessary to explore the situational simulation teaching method in the course of CRM teaching. It enable members of the learning community to interact and communicate with each other, and complete the whole process from identifying the goal to achieving the goal through their own active learning, generative learning and personal experience[4].

\section{THE CHARACTERISTICS OF SITUATIONAL SIMULATION TEACHING METHOD}

\section{A. Practicality of simulation}

The first characteristic of situational simulation teaching is the practicality of simulation, which means that the real scenes, roles, social relations, working lifestyle and so on are moved to schools and classrooms. Teachers reproduce real and specific scenes in the classroom according to the specific needs of teaching content. In the simulation scenario, students are not passive to view the role, but to personally participate in playing a specific role, acting according to the requirements of the role to be played, so as to constantly practice the corresponding role, exercise themselves, acquire knowledge and skills.

\section{B. Interaction and collaboration}

In the simulated scenario, each student plays different roles, but the roles are not isolated from each other. Each role has innumerable relationships with other roles, and the roles are interactive in behavior. In the process of implementing scenario simulation teaching method, the layout of scenarios, the role playing, the preparation of materials, the solution of problems need students to cooperate with each other, face and complete together. This process will inevitably enhance the spirit of unity and cooperation among students.

\section{Experience interest}

Students in the classroom can feel the real scene in a variety of performance, atmosphere and emotions, experience their role and work. Because this kind of experience is carried out in vivid scenes, each student simulates to play different roles, which makes the situational simulation teaching method combine teaching with pleasure, learning with pleasure, enlivens the classroom teaching atmosphere, and improves the teaching effect.

\section{Self-recognition}

Self-perception is the insight, understanding and evaluation of self. It can find own shortcomings and take evasive and remedial measures. Through the scenario simulation teaching method, students can find their own strengths so as to be in the right position and affairs, planning their own future effectively. Scenario simulation teaching method enables students to re-examine whether they are suitable for a role after role playing, reflect on whether their behavior is appropriate in a specific situation. Let students replan their career path and lifestyle in the future, recognize themselves and avoid detours.

\section{IMPLEMENTATION STEPS OF SCENARIO SIMULATION TEACHING METHOD IN THE COURSE OF CUSTOMER RELATIONSHIP MANAGEMENT}

The scenario simulation teaching method of CRM generally follows the steps of setting up scenario simulation team, preparing for scenario simulation by learning team, conducting scenario simulation in class and evaluating simulation effect. This teaching reform chooses Class 2016 of E-commerce as a pilot class, and tries to use scenario simulation teaching method in teaching methods. The specific steps are as follows:

\section{A. Setting up a situational simulated learning team}

Customer relationship management covers eight chapters: customer selection, customer development, customer information, customer classification, customer communication, customer satisfaction, customer loyalty and customer churn. Fifty six students are allowed to form eight scenario simulation teams freely according to the principle of voluntary participation. Each team chooses one of the themes to perform scenarios.

\section{B. Study teams prepare for sitcom}

After the formation of the situational simulation learning team, the members of each group need to do all the preparations before the sitcom performance in their spare time, including the selection of roles, the writing of lines, the arrangement and rehearsal of situations, the application of knowledge learned and the solution of case problems, etc. The case selection and design of scenario simulation are required according to the theme of the selected chapter. That is to say, the content of scenario simulation should meet the teaching requirements of the course Customer Relationship Management in this chapter.

In the process of sitcom preparation, teachers actively contact students, guide students, discover the problems of students in the process of extracurricular preparation timely, and give corresponding guidance and help. Under the leadership of the group leader, the students should, the students should analyses deeply under the leadership of the group leader, assign roles, complete the conception and 
writing of the scenario simulation script, and conduct simulation exercises[5].

\section{Situational simulation in class}

When the teacher has finished the teaching content of this chapter, the group that chooses the theme of this chapter will perform the scene simulation according to the prior arrangement.

In this stage, in order to make the performance more real, closer to reality and enhance the appeal of the scene, students can make simple arrangements for the classroom beforehand, such as putting on the corresponding props, water cards, preparing music, students can also wear costumes suitable for the role, so as to make the performance more appealing. At the same time, in the process of student simulation, other students are required to keep quiet. In order to ensure the integrity of the demonstration and prevent the destruction of students' thinking, teachers try not to interrupt the performance, so that the simulation can proceed smoothly according to the established goals and plans.

\section{Scenario simulation effect evaluation}

In situational simulation teaching, the final summary and evaluation is an indispensable process. In order to achieve good results in situational simulation teaching, we must not simulate for simulation. After the simulation, we must make summary and evaluation timely to help students consolidate theoretical knowledge, summarize experience, identify problems and find deficiencies, so as to digest theoretical knowledge truly, exercise ability and improve quality. Teachers can refer to the following indicators for evaluating the effect of student scenario simulation:

(1) The representation of knowledge points in scenario simulation. Whether the design of the script conforms to the theme of this chapter's Customer Relations Management course is important. Whether the treatment of knowledge points, emphases and difficulties involved in the treatment of problems conforms to the teaching content or not.

(2) Rationality of problem solving. According to the causes and consequences of scenario simulation, the teacher judges whether the solution of the problem is reasonable.

(3) Coordination of learning teams. It examines mainly the adequacy of preparation for each team, the organizational process of scenario simulation, the proficiency of the simulated content, the instrument, attitude in scenario simulation, and the enthusiasm and initiative of students.

(4) Whether scenario arrangement is reasonable or not. It examines mainly whether the scenario simulation team can solve problems, puts forward opinions to justify itself, and whether the plot is complete and attractive.

\section{IMPLEMENTING THE EFFECT OF SCENARIO SIMULATION TEACHING METHOD IN CUSTOMER RELATIONSHIP MANAGEMENT}

The use of situational simulation teaching method, students can find the solution to the problem through the form of situational reproduction to understand the rigid theory. The situational simulation teaching method in the course of Customer Relationship Management has achieved the following effects:

\section{A. Facilitating the training of applied innovative talents}

Applied innovative talents are typical compound talents. They have the basic characteristics of applied talents and innovative talents. They have strong practical application ability and certain technological innovation ability.

The introduction of scenario simulation teaching method in the course of Customer Relation Management can improve students 'practical ability effectively and innovative accomplishment of customer relationship management through students' practical participation. At the same time, innovation as a function of customer relationship management, in the teaching of Customer Relation Management is to enable students to recognize innovation and understand innovation in a series of simulated scenarios, cultivate innovative thinking, and then learn to innovate.

\section{B. Stimulating students' initiative in learning}

Through scenario simulation teaching, let students participate in the classroom, the classroom atmosphere is active, understand really why customers complain, how to deal with actively customers' complaints, how to carry out preventive management and other practical problems. By guiding the students to participate actively and adding points to the students' performance in the simulation, the students' initiative in learning can be stimulated and the teaching effect can be improved.

In a certain situation, students are easy to understand strange and difficult theories in the situation, but also willing to explore problems. The application of situational simulation teaching method by teachers can give full play to students' principal position, make students become the leading role in the classroom, and increase the opportunities for students to participate in the experience in the classroom teaching process.

\section{Students become the leading role in classroom teaching}

In situational simulation teaching, students are the leading role in classroom teaching, and teachers are the organizers and guiders of the classroom. In order to carry out the situational simulation teaching method smoothly and effectively, it requires effective communication and communication between teachers and students, students and students[6]. The traditional teaching method which focuses on teaching shows that teachers are the main body of the classroom and students are the object. The main body has formed basically its own teaching style, even though it takes into account the individual differences of students, but because of the large number of courses, it is difficult to meet the needs of students. Different from the situational simulation teaching method, students are the masters of the classroom. Teachers' role is to inspire, guide, prompt, summarize, etc. Through students' self-induction and summary, students have a deeper understanding of the problem. 


\section{Students have realized the transformation from knowledge to ability}

As we all know, the purpose of learning knowledge is to transform knowledge into wisdom and ability, so as to solve the problems encountered in reality. Scenario simulation teaching method can realize the transformation from knowledge to ability. In the simulation, it not only improves the analysis ability of professional perspective, but also improves the students' organizational ability, language expression ability, team cooperation ability and stage performance ability, which is conducive to overcome students' tension.

\section{E. Students are able to comprehend the knowledge what they have learned.}

The main body of scenario simulation teaching is students. Students should play a role in various simulated scenarios. This requires students to collect fully detailed information and materials of customer relationship management, consider the integration of knowledge points to be learned and mastered in the textbooks, especially the key and difficult problems, and try to integrate them together. In this way, we can not only review the knowledge what we have learned, but also improve the students' ability to use knowledge comprehensively, so that students can turn passive learning into active learning. Situational teaching method enables students to gradually integrate into the actual role of customer relationship management, to communicate effectively with customers, customer complaint handling and other preliminary understanding and experience, greatly mobilizing students' enthusiasm, initiative and enthusiasm for learning.

\section{SUMMARY}

The implementation of scenario simulation teaching method does not mean that the traditional teaching mode with basic theoretical knowledge as the core is neglected. On the contrary, the use of this method not only strengthens the learning of basic theoretical knowledge, but also lays a solid foundation for the development of scenario simulation teaching.

Situational simulation teaching method requires students to assume themselves as a role in a particular situation, and then students play this role in the role-playing. In the process of situational simulation teaching, for teachers, they should be learners themselves when they change from information providers to "learning partners" of students. Teachers can not become experts on every problem that students choose. Therefore, teachers should be learners as well as students. For students, the process of situational simulation teaching method is not only for the acquisition of ordinary grades, but also to help them improve their ability to effectively exchange ideas and discuss with others.

Situational simulation teaching method embodies the teaching idea and thought of "teacher-led fully, studentoriented", stimulates students' learning enthusiasm and initiative, and provides a platform for students to fully grasp and flexibly use the theoretical knowledge they have learned. Of course, situational simulation teaching method is not omnipotent, and it needs to be used in conjunction with other teaching methods to achieve complementary results. Moreover, the teaching method of scenario simulation needs to be explored and practiced continuously, and it needs to be improved in guiding students to select scenarios and show better performance effects.

\section{REFERENCES}

[1] Li Lei. Research on the Reform of Home Economics Teaching Practice in Colleges and Universities Based on "Case Teaching + Situationa Simulation" Model [J]. Journal of Jilin Institute of Education, 2013, (11).

[2] Liang Yisheng. Application of scenario simulation teaching method in college students' interview teaching [J]. China Electric Power Education, 2009, (02).

[3] Zeng Zhiyun. Situational simulation teaching research of Management Science [J]. Journal of Higher Education Research, 2009, (03)

[4] Liu Bo. Application of Scenario Simulation in Human Resource Management [J]. Management Observation, 2014, (02)

[5] Zhou Yinghui. Study on the Characteristics and Application of Situational Simulated Teaching Method --- Taking "Ideological and Moral Cultivation and Legal Basis" as an Example [J]. Heilongjiang Higher Education Research, 2011, (07)

[6] Liu Chen, Fu Qiufeng. The application of scenario simulation teaching method in the teaching of management courses in Colleges and universities [J].Science and Education Educational Journal (mid-term), 2015, (07) 